\title{
ETO Standardization Strategies: Verifying Implementation and Effect
}

\author{
Christian Alexander Bertram ${ }^{1}$, Georg Otto Mueller ${ }^{1}$, Niels Henrik Mortensen ${ }^{1}$ \\ ${ }^{1}$ Technical University of Denmark \\ chalbe@dtu.dk \\ gemul@dtu.dk \\ nhmo@dtu.dk
}

\begin{abstract}
Engineer-To-Order product development often entails project-based development of highly customized products with a production of low volumes. Unique designs increases the interest for re-use to keep costs down and profits high. Companies are employing efforts such as standardization to achieve this. Benefits can be signifcant if the implementation strategy is correct. This paper presents an approach for assesssing this standardization implementation strategy. The work is founded in an industry case study with the same objective and from this work a generic approach is described.
\end{abstract}

Keywords: concurrent engineering (CE), decision making, design strategy, standardization

\section{Introduction}

Contrary to other production business forms, Engineer-To-Order (ETO) companies work with customization as a central part of their business. Products are done on a project-by-project basis and are tailored specifically to the requirements of each individual customer (Hobday, 2000; Wortmann, 1992). This is often done by modifying existing designs or collecting sub-solutions from previous projects. The solution space and solution complexity are ever expanding and increasing by the order (Fisk, 2013).

To decrease the amount of repeated work, decrease waste-work in the organization and cope with increasing complexity, ETOs attempt to improve their product creation by various means of portfolio rationalization and management strategies. This includes, but is not limited to: Standardization, modularization, platform based design, mass customization and configuration 
(Gepp et al., 2015; Hicks et al., 2000; Willner et al., 2016). Common for these initiatives is, that they introduce control measures to the workflow, guiding designers towards standardized solutions, fixed module packages, technology platforms or configurable design solutions. This is done to improve sales delivery times, decrease project risk and ultimately to increase the profitability of project execution (Haug et al., 2014; Robertson and Ulrich, 1998).

There is more to portfolio management than simply labeling preferred solution variants. It entails investigating and defining superior solutions, both functionally, financially and operationally. Once defined, they need to be sufficiently embedded in the project execution workflow. Incentives can be offered to the organization to make it attractive to use them, e.g. lower price tags or reduced lead time. However, those benefits must be balanced out by benefits somewhere else in the project lifecycle e.g. by increased productivity or lowered manufacturing costs. These optimizations can be found internally (e.g. via improved manufacturing or bulk purchase) or externally (e.g. negotiated standard deals with suppliers). Ultimately there is a whole system of integrationable considerations around the implementation of standardization strategies. It is this system that this article aims to elaborate upon.

A study was conducted in collaboration with an ETO company to evaluate the standardization implementation of design standards introduced into the organization long ago. That study involved a series of steps undertaken to assess the current state of the standardization strategy. Based on that study, this paper describes the generalized method and how other businesses can evaluate their own implementation of standardization strategies. This paper proceeds as follows: The foundations in state-of-the-art research of ETO standardization are described in section two. Section three describes the proposed standardization implementation method and the considered evaluation aspects along with case-specific execution details. Section four follows up with a discussion of the challenges and benefits of this approach. The method and use is concluded in section five.

\section{Background}

For this study, two major topics of literature have been reviewed; (1) ETO standardization strategies and the attempt to rationalize portfolios and processes to streamline designs towards efficiency and profitability and (2) Evaluation of portfolio standardization efforts. Furthermore, experience is drawn upon from a case study concerning design standardiation evaluation together with a collaborating case company.

\subsection{Literature Review}

Engineer-To-Order (ETO) businesses are increasingly employing portfolio rationalization and management strategies to mitigate variance and control the internal process and product variance. They have proven to bring significant benefits such as efficient engineering, cost reductions or lead time shortenings (Gepp et al., 2016; Jiao et al., 2007; O'Connor et al., 2015). Increased market share, simplified operations and reduction of complexity are also goals of standardization efforts (Wang et al., 2016). Concerned that it might sacrifice innovation, they find that standardization has a positive impact on innovation, mass customization and delivery speed. (Gepp et al., 2016) discuss the difficulty in introducing such programs in this highly complex product category. Especially the importance of choosing the right evaluation measures and the long timeframe before the benefits from the standardization program register on the account. 
(Gepp et al., 2014) investigates best-practices for standardization efforts in the Engineer-ToOrder business of plant engineering. Six company cases are reviewed and their best practices are split into the following categories: Strategy, Process, Workflow, Tool and Technical Solution. Amongst the best practices are: (Strategy) Show the value proposition of the program. (Process) Ensure long-term organizational implementation. (Tool) Integrate IT-landscape, create seamless tool chain. (Johnsen and Hvam, 2018) suggest an approach for understanding and estimating the impact of non-standard customizations. This is done in two steps, by first (1) assessing complexity of solutions and deriving a complexity-index for non-standard customizations and then (2) deriving an impact model which translates operational aspects into an equation that returns the impact. The approach is founded in theory and tested with an ETO case company. (Bonev and Hvam, 2013) explores the strategies of mass customization and how these efforts can be measured. The approach focuses on the efficiency of project execution and how design processes are changed when customizing solutions. This is done in four phases: (1) Setting the scope of the analyses to a subset of product families. (2) Assessing pre-calculations of the projects to set a performance baseline. (3) Comparing with post-calculations to assess how well financial, delivery, process and product estimates were met and lastly (4) creating a plan of action based on the capabilities of the mass customization efforts. In essense a comparisson of intended potentials and actually realized benefits.

The reasons for standardization are often similar, but the implementation can be vastly different. Researchers have proposed different key steps to increase the likelihood of a powerful and lasting effect of standardization efforts. Standardization initiatives have to be integrated into the totality of processes, the organization and departments (e.g. functional teams). Lack of proper integration is one of the key reasons for effects and benefits of such initiatives. (Foehr et al., 2015; Gepp et al., 2015). In the case of standardization of technical publications, (Burgess, 1992) suggest four evaluation criteria for effective implementation in order to improve productivity and customer satisfaction: Clearly communicate the standards, make them readily available, train employees to use them and maintain the standards. The impact of standardization also needs to be apparant in the organization. If the reasons for standardization is not apparent, it is more difficult to pursuade its use. (Sinigalias and Dentsoras, 2013) proposes an automated method of evaluation the alignment of digital mechanical designs and organizational (govermental, non-govermental, international, etc) design standards e.g. ISO standards. The implementation of such a measure is intended to reveal how well the actual product matches the guidelines set out for that type of product.

\subsection{Industry Case}

Besides state-of-the-art research, experiences from casework with a collaborating company supported the proposed evaluation method. The authors undertook a similar evaluation together with this company and the study described in this paper originates partly from this work.

The company works by Engineer-To-Order principles, with products of low volumes and high degrees of variation. The company works primarily in project-based workflows and is the main project driver all the way from customer discussions to finished operational products. The products are highly complex processing facilities, designed specifically for individual customer companies. Their designs are often modified versions of previously conducted projects or collections of sub solutions from multiple previous solutions. The company employs design guidelines for their engineers and wants to evaluate the impact of those guidelines and the overall benefit they supply for the project teams and the project financials. A function model with inputs, outputs, supports and controls was created. It supplied the process overview for 
identifying all process where design standards are reviewed in relation to the design task. The evaluation was done partly through review of available project documentation and partly through interviews with relevant company stakeholders and interestees.

\subsection{Contribution}

The importance of standardization and variety management is widely documented, as is the advice and considerations when introcing such strategies. Once the strategy has been formulated, introduced to the organization, and implemented in the business processes, it is oftentimes left untended to bring about the promised beenfits. However, properly retrospectively investigating and evaluating this implementation can expose misalignments, missed opportunities or neglects. It can reveal how to further improve a succesful strategy or how to save a failed attempt. The authors have been unable to identify a structured approach for evaluating the implementation of engineering design standardization strategies.

\section{Evaluating Standardization Strategies}

Portfolio rationalization and management initiatives are powerful if thoughtfully implemented and rigorously maintained. There are powerful benefits to gain from optimized standardized processes. However, challenges such as integration, communication and lack of governance can diminish the produced effects. From the presented literature and case work with an ETO plant engineering company, five aspects of standardization strategy assessment are introduced. Figure 1 illustrates these five aspects and how they form a coherent view of the standardization implementation strategy in the process of product creation.

A. Availability. The possibility and ability for every relevant stakeholder to access the standardized information.

B. Bond. The connectivity between instances of design standards and standardized information, ensuring that all instances are aligned and free of ambiguity or conflicts.

C. Compliancy. The level of strictness to which the conducted design work abide by the defined design standards.

D. Drive. The downstream benefits from using the standards and the direct reasoning behind implementing the design standards.

E. Encouragement. The direct benefits and incentives for the use of the design standards and standardized information i.e. from the individuals or team's perspective.

Elaborating on these five aspects for the specific business or within a branch or the organization will supply an as-is perspective on the state of standardization. It can pinpoint any potential improvement potentials or reveal possible misalignments between departments. The five aspects are described in more detail in below sections, howeve the findings for each aspect should be brought together for a combined review of the current state of the company's standardization strategy. 


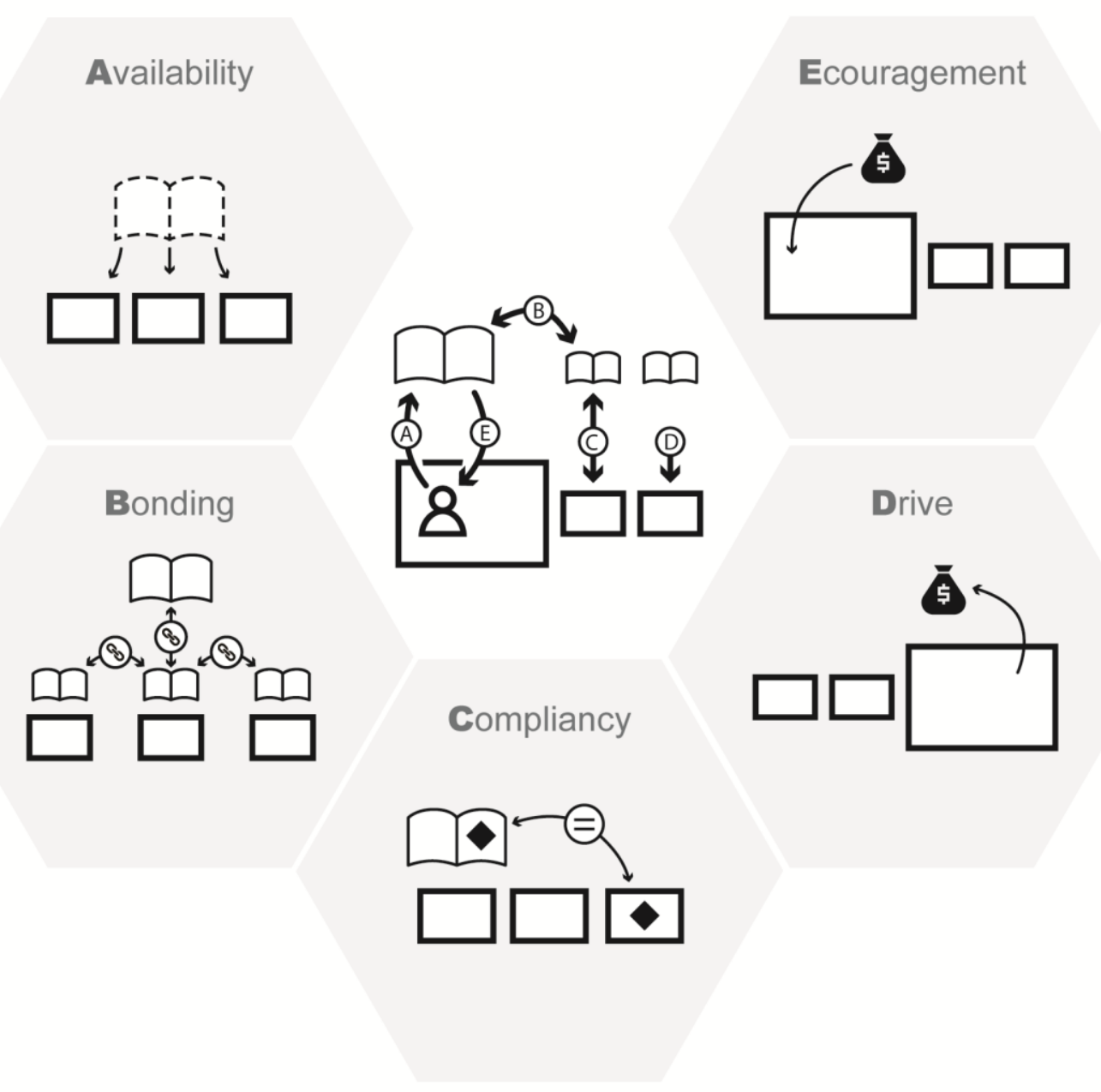

Figure 1: The five aspects of assessing the standardization implementation strategy. (A) Availability of standard information. (B) Bonding between several instances of this information. (C) Compliancy of processes and products to the standards. (D) Drive to standardize. (E) Encouragement to use the standardized information.

\subsection{Availability}

The access to standardized information and presence of design standards is labeled Availability.

As a backbone for the study, the product creation processes were mapped out using the IDEF0/IDEFØ function modelling language. This language is widely used for mapping process interaction, activity sequences, decision dependencies, etc. (Hanrahan, 2007; Kovács, 2016; www.idef.com, n.d.). Figure 2 presents the basic IDEFØ structure and building blocks. The basic element of this language is a process block with four connection faces: Left represent inputs; right represent outputs; support functions are entering from the bottom: control measures are entering from the top. This can illustrated with the example shown on Figure 2 (B): A design engineer is tasked with the creation of a structure. He receives the design specification (input) and returns his finished structure design (output). To enable his work he is using a CAD software tool (support) and he has to abide by ISO standards and internal design libraries (control). 

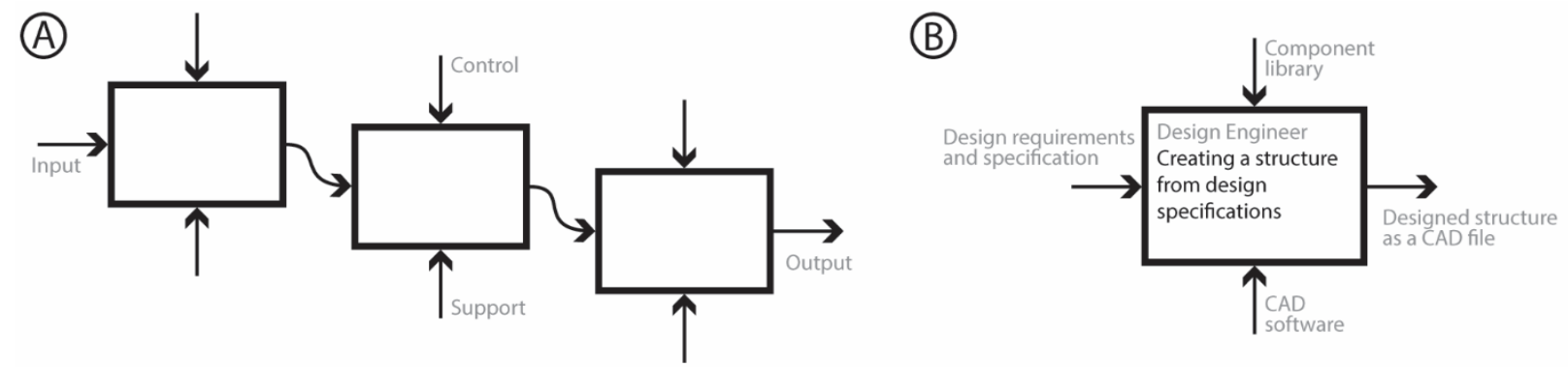

Figure 2: (A) Function modelling based on IDEF0/IDEFØ. (B) An example of the IDEF function modelling with the task of a design engineer.

With the function/process model sequence in place, the control measures can be added specially the relevant design standards must be accounted for. The added design standards must be sufficiently specific to allow further analysis if their contents, hence simply stating that that a proces uses „Standards“ is not sufficient, the information must be specified to the individual documents or libraries used for this specific control.

The key process responsible or project stakeholders should be able to point to a specific source of standard information and design standards, in order for them to use the standard information for product development projects. If this is not possible, then consider creating clear maps for standard information for each business process and work group to ensure everyone knows where they can find this information.

\subsection{Bonding}

With the process model in place with control measures identified, the content of these controls must be compared to ensure that they are aligned and they do not supply ambiquos standardization information. If there are several access possibilities for information and that informaiton is not connected, there is a risk of multiple sources of conflicting information. That can lead to misalignments between departments and design errors.

To determine the bonding of design standards for the undertaken case study, two different approaches were employed; (1) Discussions about the access and use of standards with product development and execution groups and (2) Interviews with primary responsible parties for the design standards and the distribution of these into the organization. These types of qualitative assessment provided insight into the landscape of current design standards - how they were accesses, how they were interelated and how information was updated.

\subsection{Compliancy}

A standard only has the effect of its use. The use of the supplied design standard information must be assessed. This can be done by checking the compliancy of the business processes, verifying that the prescribed information is also the information ending up in the created product.

To determine the use of the standards in the case study, the dimensions and features of the created component drawings were compared to prescribed dimensional values in the design standards. All relevant dimensions were collected and the frequency of every size was plotted as histograms with standard and non-standard options marked. It was then visible how many components that were compliant with the standards and how many that were not. 


\subsection{Drive}

Standard designs must have a merit for existence, for instance as improved efficiency in later project stages, cost reductions in supplier deals or to guarantee the functionality of the product In any case, the reasons for standardization must be clear. The reasoning behind standardization must be communicated to the organization. If the organization is not aware of the reasoning behind the controls, then they might quickly be neglected.

The Drive can be assessed by stepping through the subsequent processes in the business flow and identifying any links to the design standards. For instance, interviewing primary stakeholders in manufacturing and discussing potential process changes or implications of standard versus non-standard designs. The primary goal is to determine whether it makes a difference if the standards are present or not. Discussing the Drive with primary stakeholders of internal processes and possibly key supplier stakeholders can verify intended drivers for standardization or reveal new potential drivers.

If sufficient data is available, correlation analysis can be done between the Compliancy to the standards and the effieiency/cost/lead time of those subsequent processes. In case the primary driver for the design standards are reduced manufacturing cost, there should be a clear link between products that fully adher to the standards and matching low production cost for those products. The research topics of Complexity Cost can be of interest for managers looking into the drivers of standardization (Hansen et al., 2012).

\subsection{Encouragement}

Encouragement is the direct reasoning for the individuals or teams in the organization to abide by the standards. It covers benefits that are are transferred back into the product creation process. If procuring from a standard catalogue enables faster manufacturing and lower supplier costs, then some of those benefits can be transferred to the specific product development project as incentives. When project teams receives direct benefits from working within the standardized solution space, those incitements can be used to persuade customers and other project stakeholders to align. Promises of faster delivery times and even discounts are powerful tools to make standard offers more attractive than more custom products with longer waiting time and more expenses.

The encouragement is the indivual's incentive to adhere to design standards, meaning that the role of the design standards in the everyday work should be discussed with design teams, project managers, sales peronnel, etc. If management protocols are done within the organization, they too can hold information about any incentives offered to the project execution teams as a result of their use of standards. It is rather the presence or absence of Encouragement that is the matter and less the exact quantification of those incentives.

\section{Discussion}

With the approach for standardization evaluation presented, this sections dives into a few of the questions left unanswered.

\subsection{Different Strategies of Standardization}

This study focuses on the standardization scheme where project teams early on can pick from standard solutions or continue on with customized solutions. It is also assumed that the 
reasoning for standardization can be directly seen downstream in the project lifecycle. Other forms of standardization exists (Meyer and Lehnerd, 1997; Robertson and Ulrich, 1998). If the goal is to allow colaborative work with other companies or to fit industry platforms, then the benefits are seen in market share and sales instead of manufacturing. Though it still fits the nomenclature of Drive and Encouragement, the process flow map will have to include those external parties e.g. different markets and companies. The use and benefits from the implemented standards should still be identifiable by the proposed five evaluation aspects.

\subsection{Translating Drive into Encouragement}

As described in the proposed approach, some of the drivers for standardization e.g. reduced manufacturing cost or faster delivery times, should be transferred to the project execution as benefits and thereby encouragement to abide by the standardized solutions.

Manufacturing efficiency or strategic choices for certain design choices can result in major benefits. The balance of what benefits belong to the business and which should be passed on to teams or customers is difficult. If everything is passed on, it is essentially only the customer who benefits. If nothing is passed on and the company takes all the rewards, they risk the standards are never used because there is no encouragement.

\subsection{Project Based Product Development}

Companies employing project-based product development are more inclined to have a certain independency in their project execution. Project teams can work for years on single projects and have little exchange between project streams. This increases the importance for proper management to align the streams and make sure the company is not working itself in ten different directions. Hence rationalization efforts e.g. standardization becomes increasingly important.

\subsection{Choosing Evaluation Aspects}

For this evaluation framework, the five aspects Availability, Bonding, Compliancy, Drive and Encouragement were chosen as the authors found that those five summarized much of the research in the field of evaluation of portfolio management initiatives. Furthermore, it was derived from the author's experiences with working with ETO case companies.

\subsection{Future Work}

The authors would appreciate more cases to trial this approach. Alternative they hope for other interested researchers to test this approach in other industry cases. Furthermore, the authors expect to refine the method, perhaps defining criteria and criteria evaluation guidelines for each of the evaluation aspects, to further support its use.

\section{Conclusion}

To control the high levels of variety and customization in Engineer-To-Order businesses, they are employing rationalization strategies such as standardization initiatives. Many of such initiatives are succesful but only a fraction of them remain succesful long-term for various reasons. To assess if the implemented standardization strategy is effective, five evaluation aspects are proposed. The aspects are founded in literature and a case study with a similar objective: To asses the use and compliancy of standard design guidelines at an Engineer-To- 
Order company. The five aspects include: (A) Availability of the standardized information for processes and project stakeholders; (B) Bonding of separate instances of standardized information; (C) Compliancy of both processes and products to the standards; (D) Drivers for the business to do standardization; (E) Encouragement for the project stakeholders to use the offered standard solutions. These five aspects can be decribed in a stepswise manor starting of with a map of the product creation flow and the control measures used to stear products and processes toward a standard solution. The authors aspire to test this approach in other cases.

\section{References}

Bonev, M. and Hvam, L. (2013), "Performance measures for mass customization strategies in an ETO environment", Proceedings of the 20th EurOMA Conference, European Operations Management Association.

Burgess, G.J. (1992), "Communication engineering standards: Implementing for effectiveness", IPCC 91, IEEE, pp. 50-52, DOI:DOI:10.1109/ipcc.1991.172731.

Fisk, D. (2013), “Engineering complexity”, DOI:DOI:10.1179/030801804225012617.

Foehr, M., Gepp, M. and Vollmar, J. (2015), "Challenges of system integration in the engineerto-order business", IECON 2015 - 41st Annual Conference of the IEEE Industrial Electronics Society, IEEE, pp. 73-79, DOI:DOI:10.1109/IECON.2015.7392078.

Gepp, M., Foehr, M. and Vollmar, J. (2016), "Standardization, modularization and platform approaches in the engineer-to-order business - Review and outlook", 2016 Annual Ieee Systems Conference (Syscon), IEEE, pp. DOI:DOI:10.1109/SYSCON.2016.7490549.

Gepp, M., Foehr, M., Vollmar, J., Schertl, A. and Schaeffler, T. (2015), "System integration in modularization and standardization programs", 2015 Annual IEEE Systems Conference (SysCon) Proceedings, IEEE, pp. 847-852, DOI:DOI:10.1109/SYSCON.2015.7116856.

Gepp, M., Vollmar, J. and Schaeffler, T. (2014), "Standardization programs in the industrial plant business: Best practices and lessons learned", 2014 IEEE International Conference on Industrial Engineering and Engineering Management, IEEE, pp. 122-126, DOI:DOI:10.1109/IEEM.2014.7058613.

Hanrahan, R.P. (2007), "The IDEF Process Modeling Methodology", Accessed at http://www.sba.oakland.edu/faculty/mathieson/mis524/resources/readings/idef/idef.html the $24 / 5 / 2020$.

Hansen, C.L., Mortensen, N.H. and Hvam, L. (2012), "Calculation of Complexity Costs - An Approach for Rationalizing a Product Program", Proceedings of NordDesign Conference 2012.

Haug, A., Hvam, L. and Mortensen, N.H. (2014), "Reducing variety in product solution spaces of engineer-to-order companies: the case of Novenco A/S", International Journal of Product Development, Vol. 18 No. 6, p. 531, DOI:DOI:10.1504/ijpd.2013.058556.

Hicks, C., Earl, C.F. and McGovern, T. (2000), "An analysis of company structure and business processes in the capital goods industry in the UK", IEEE Transactions on Engineering Management, Vol. 47 No. 4, pp. 414-423, DOI:DOI:10.1109/17.895337.

Hobday, M. (2000), "The project-based organisation: an ideal form for managing complex products and systems?", Research Policy, Vol. 29 No. 7-8.

Jiao, J., Simpson, T.W. and Siddique, Z. (2007), "Product family design and platform-based product development: A state-of-the-art review", Journal of Intelligent Manufacturing, Vol. 18 No. 1, pp. 5-29, DOI:DOI:10.1007/s10845-007-0003-2.

Johnsen, S.M. and Hvam, L. (2018), "Understanding the impact of non-standard customisations in an engineer-to-order context: A case study", International Journal of Production Research, DOI:DOI:10.1080/00207543.2018.1471239.

Kovács, G. (2016), "Process Description Languages in Construction Logistics", Vol. 44 No. 1, 
pp. 50-59, DOI:DOI:10.3311/PPtr.8207.

Meyer, M.H. and Lehnerd, A.P. (1997), The Power of Product Platforms: Building Value and Cost Leadership, New York: The Free Press.

O'Connor, J.T., O’Brien, W.J. and Choi, J.O. (2015), "Standardization Strategy for Modular Industrial Plants", Journal of Construction Engineering and Management, Vol. 141 No. 9, p. 04015026, DOI:DOI:10.1061/(ASCE)CO.1943-7862.0001001.

Robertson, D. and Ulrich, K. (1998), "Planning for Product Platforms", Sloan Management Review, Vol. 39 No. 4, pp. 19-31, DOI:DOI:Article.

Sinigalias, C. and Dentsoras, A. (2013), "Evaluation of Standardization Level of Mechanical Systems in Engineering Design", Internation Conference on Engineering Design (ICED13), pp. 1-10.

Wang, Z., Zhang, M., Sun, H. and Zhu, G. (2016), "Effects of standardization and innovation on mass customization: An empirical investigation", Technovation, Elsevier, Vol. 48-49, pp. 79-86, DOI:DOI:10.1016/j.technovation.2016.01.003.

Willner, O., Powell, D., Gerschberger, M. and Schönsleben, P. (2016), "Exploring the archetypes of engineer-to-order: an empirical analysis", International Journal of Operations and Production Management, Vol. 36 No. 3, DOI:DOI:10.1108/IJOPM-072014-0339.

Wortmann, J.C. (1992), "Production management systems for one-of-a-kind products", Computers in Industry, Vol. 19 No. 1, pp. 79-88, DOI:DOI:10.1016/01663615(92)90008-B.

www.idef.com. (n.d.). "Integrated DEFinition Methods (IDEF)", Accessed at www.idef.com the $24 / 05 / 2020$. 